\title{
Characterization of the materials and techniques of a birthday inscribed lacquer plaque of the Qing Dynasty
}

Liping Zheng ${ }^{1,2}$, Liqin Wang ${ }^{1 *}$, Xing Zhao ${ }^{1}$, Jiali Yang ${ }^{2,3}$, Mengxia Zhang ${ }^{2,4}$ and Yunfu Wang ${ }^{2}$

\begin{abstract}
In this study, in order to analyze the materials and techniques used for the production of the inscribed plaques, multianalytical scientific approach, including optical microscopy (OM), scanning electron microscopy with energy dispersive X-ray spectroscopy (SEM-EDS), X-ray diffraction (XRD), micro-attenuated total reflection Fourier transform infrared spectroscopy ( $\mu$-ATR-FTIR), and micro-Raman spectroscopy ( $\mu$-Raman), were used to explore the materials and techniques utilized to create the "Chun Rong Xuan Mao" birthday inscribed plaque of the Qing Dynasty. The results showed that the plaque was made of cypress wood and decorative parts consisting of the surface lacquer layers, plaster lacquer layers and primer lacquer layers. Chinese lacquer was the principal material used in the surface lacquer layers; gypsum and Chinese lacquer were the materials used in the plaster lacquer layers; and the primer lacquer layers was composed of Chinese lacquer, calcite, and mixed pigments by cinnabar and minium. The surface lacquer layers of the inscribed plaque were lacquered black. Gypsum lacquer plaster has been commonly used in the ground layer of lacquerware in modern history. This study confirmed the existence of technology to make lacquerware using gypsum lacquer plaster in the Bashu area during the late Qing Dynasty. Moreover, this study not only provides new findings regarding the traditional production of inscribed plaques and offers technical support for the protection and restoration of such plaques but also has great significance to exploring the history of ancient techniques of lacquering and decorating lacquerware.
\end{abstract}

Keywords: Inscribed plaque, $\mu$-FTIR, $\mu$-Raman, XRD, SEM-EDS, Materials, Techniques

\section{Introduction}

Inscribed plaques, hung on the lintel of a door, are integral parts of ancient Chinese architectures and unique cultural symbols of China. As an artistic form integrating language, calligraphy, lettering, architecture and sculpture, inscribed plaques contain rich information about historical culture and traditional craftmanship. Birthday inscribed plaques were gifts to the elderly on their birthdays to wish them longevity, and the custom of sending birthday plaques has been popular in China ever since the Tang Dynasty, reflecting the traditional virtues of

\footnotetext{
*Correspondence: wangliqinnwuedu@163.com

1 School of Cultural Heritage, Northwest University, Xi'an 710127, China

Full list of author information is available at the end of the article
}

the Chinese nation. The Bashu area is a region currently under administration of Sichuan Province and Chongqing Municipality. In this area,there is a large number of inscribed plaques, especially Chinese famous inscribed plaques. In the Northern Song Dynasty, Li Xie documented the dimensions of different inscribed plaques in his book Ying Zao Fa Shi(营造法式) [1], but he did not mention the materials. Based on the variation in the standard length of Chinese rulers throughout the ages, the average dimension of inscribed plaques in the Song Dynasty was $61-215 \mathrm{~cm}$ high and $45-172 \mathrm{~cm}$ wide, indicating that the plaques were presented mostly in a vertical alignment. During the Ming and Qing Dynasties, as the development of inscribed plaques peaked, their sizes became larger, and the plaques were presented mainly in a horizontal alignment. The techniques used
Springer Open

(c) The Author(s) 2020. This article is licensed under a Creative Commons Attribution 4.0 International License, which permits use, sharing, adaptation, distribution and reproduction in any medium or format, as long as you give appropriate credit to the original author(s) and the source, provide a link to the Creative Commons licence, and indicate if changes were made. The images or other third party material in this article are included in the article's Creative Commons licence, unless indicated otherwise in a credit line to the material. If material is not included in the article's Creative Commons licence and your intended use is not permitted by statutory regulation or exceeds the permitted use, you will need to obtain permission directly from the copyright holder. To view a copy of this licence, visit http://creativeco mmons.org/licenses/by/4.0/. The Creative Commons Public Domain Dedication waiver (http://creativecommons.org/publicdomain/ zero/1.0/) applies to the data made available in this article, unless otherwise stated in a credit line to the data. 
in producing an inscribed plaque generally included woodworking, carving, creating the ground layer, lacquering, screening, and tracing words. As the only existing monograph about lacquering in ancient China, Xiu Shi $L u$ (髹饰录), written by Huang Cheng [2], explains the raw materials and techniques of lacquering in great detail, providing a reliable basis for the naming and classification of ancient lacquerware. To show respect for the elderly, inscribed plaques used at birthday ceremonies were made of exquisitely selected materials with excellent craftsmanship. These inscribed plaques were fine works of lacquering at that time.

Under long-term weathering conditions, a considerable number of inscribed plaques deform, the words fade, and the decorative parts deteriorate. To help preserve these cultural relics, it is of great importance to study the material composition, the production techniques, and the scientific cognition. Based on the principle of minimum intervention, the original materials and techniques should be used for cultural relic restoration. Although there has been an increasing number of studies about the materials and techniques used in ancient wall paintings $[3,4]$, colored paintings [5, 6], and lacquerware [7-9], no study has been carried out on the materials and techniques used to create inscribed plaques. Therefore, in this study, we used a number of multi-analytical scientific technologies, including optical microscopy (OM), scanning electron microscopy with energy dispersive X-ray spectroscopy (SEM-EDS), micro-attenuated total reflection Fourier transform infrared spectroscopy $(\mu$-ATRFTIR), X-ray diffraction (XRD), and micro-Raman spectroscopy ( $\mu$-Raman) to analyze microsamples that fell off of the "Chun Rong Xuan Mao" birthday inscribed plaque in the Bashu area during the reign of Tongzhi Emperor of the Qing Dynasty. The study provides new evidence for the traditional production techniques utilized to create inscribed plaques and offers technical support for the protection and restoration of inscribed plaques. Thus, this study is of great significance to exploring the history of ancient techniques for lacquering and decorating lacquerware.

\section{Experimental}

The inscribed plaque and samples

Figure 1a shows the "Chun Rong Xuan Mao" birthday inscribed plaque produced in the Bashu area of China in the 5th year during the reign of Tongzhi Emperor of the Qing Dynasty (A.D. 1866). With a size of $215 \times 70 \times 4 \mathrm{~cm}$, the inscribed plaque is well preserved as a whole, with localized damage in several places. It has a visually black surface with no linen or cloth in the ground layer. Four Chinese characters, “椿荣萱茂” (“Chun Rong Xuan

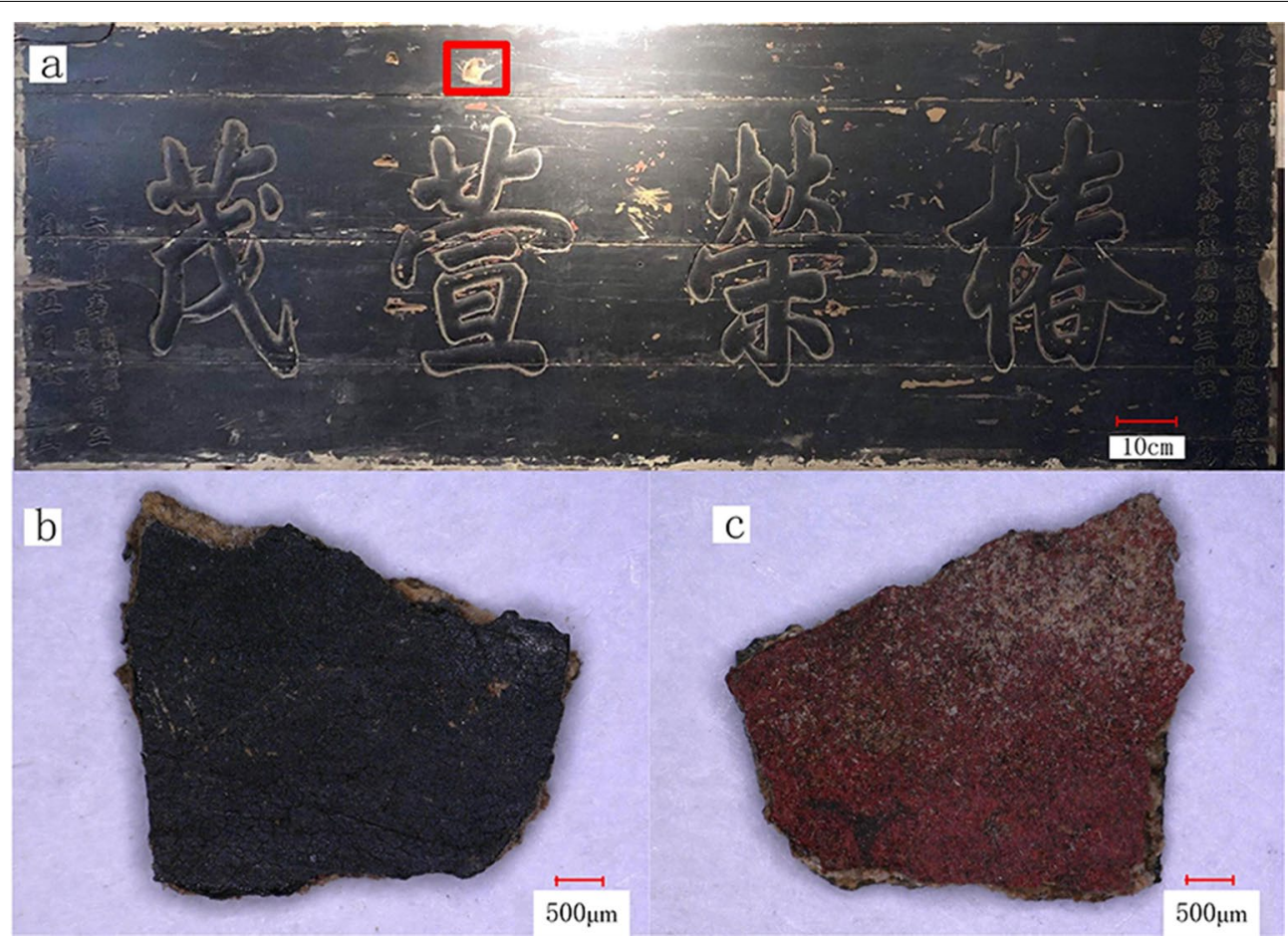

Fig. 1 The "Chun Rong Xuan Mao" plaque and microscopic images of the microsamples: a Front of the plaque. b Microscopic image of the front side of a microsample $(50 \times$ magnification). c Microscopic image of the back side of the microsample (50 $\times$ magnification) 
Mao"), were inscribed on the plaque. "Chun" refers to the Chinese toon. "Xuan" is a day lily, believed by ancient Chinese people to be a plant that helps one forget about sad things. In ancient China, a father was referred to as “Chunting”(椿庭), and a mother was called "Xuantang" (萱堂). Thus, “Chun Rong Xuan Mao" means prosperity of the Chinese toon and flourishing of the day lily, which is a metaphor for the longevity of parents. According to the inscriptions, it is known that the inscribed plaque was presented by an individual as a gift to his parents at their 60th birthday. The 4 Chinese characters were inscribed by an official of second-grade rank in the feudal regimes.

The microsamples were fragments that fell off the plaque. With irregular shapes, the microsamples had a maximum size of $1.2 \times 1.0 \times 0.1 \mathrm{~cm}$ and a minimum size of $0.9 \times 0.4 \times 0.1 \mathrm{~cm}$. The colour of the front (surface) of the microsample is black (Fig. 1b), and that of the back side of the microsample is dark red with a white layer (Fig. 1c).

\section{Equipment and experimental conditions Optical microscopy}

OM was used to observe the microsamples and identify the wood species of the base materials. Specifically, the surface and microlayer were analyzed with a 3D ultradepth-of-field VHX-6000 microscopic system (Keyence Corporation, Japan) that has a 20-200 $\times$ VH-Z20T ultraminiature zoom lens, a $1 \mu \mathrm{m}$ automatic resolution in the $\mathrm{Z}$ axis, and an electric $\mathrm{XY}$ table. To identify the wood species of the base materials, a BX51 microscope (Olympus Corporation, Japan) was used to observe the structure of wood cells.

\section{Scanning electron microscopy with energy dispersive X-ray spectroscopy}

For the SEM-EDS analysis, an FEI Quanta 450 FEG scanning electron microscope and X-MaxN50 energy dispersive X-ray spectroscopy (FEI Company, USA) were used to analyze the morphology and elements of the microsamples.

\section{Micro-attenuated total reflection Fourier transform infrared spectroscopy}

For the $\mu$-FTIR analysis, a LUMOS microscope (Bruker, Germany) was used to analyze organic and inorganic substances in the microsamples. The instrument had a spectral range of $4000-600 \mathrm{~cm}^{-1}$ and a spectral resolution of $4 \mathrm{~cm}^{-1}$. With 16 times scanning and $8 \times$ magnification, the measurement micro-area was adjusted between 100 and $10 \mu \mathrm{m}$ using a $100 \mu \mathrm{m}$ (diameter) ATR crystal (germanium) tip.

\section{X-ray diffraction}

A Smartlab rotating target X-ray diffractometer equipped with micro-area optical components (Rigaku Corporation, Japan) was used for the XRD analysis to analyze the phase composition of the microsamples. It has a maximum power of $9 \mathrm{~kW}$ and an XY sample table, and metallic copper was used as the rotating target.

\section{Micro-raman spectroscopy}

For the $\mu$-Raman analysis, an inVia micro-Raman spectrometer (Renishaw, UK) was used to identify the composition of samples in the micro-area. It has a wavenumber range of $100-2000 \mathrm{~cm}^{-1}$ and a spot size of $1 \mu \mathrm{m}$. A $785 \mathrm{~nm}$ laser source was used for irradiation $(3-8 \times)$ for a total duration of $10 \mathrm{~s}$.

\section{Experimental methods}

Each sample was placed on the sample table for SEM-EDS, $\mu$-FTIR, XRD, and $\mu$-Raman analyses. To perform microstratigraphic analysis, the sample $(0.4 \times 0.4 \times 0.1 \mathrm{~cm})$ was cross-sectioned. Specifically, the sample was first vertically embedded in $A B$ glue made from epoxy resin (Shanghai Naibo Co., Ltd., China). After solidifying at $25^{\circ} \mathrm{C}$ for $3-4 \mathrm{~h}$, the epoxy resin was polished with 200-, 800-, 3000-, and 7000-grit sandpaper imported from Germany and 12000-grit sandpaper imported from the US. The cross-sections were observed under a microscope to obtain the microstructure characteristics and to identify the wood species.

\section{Results and discussion}

\section{Observation of the cross-section}

Figure 2a shows a SEM image of the surface layer of the plaque. The particles are fine and glossy, and there is a large number of irregular cracks, through which the ground layer could be seen. The appearance of cracks on the surface layer indicates deterioration of the decorative parts. Figure 2b, c show the SEM and OM images of cross-section, in which 8 microstratigraphic sequences are observed (L1-L8) (Table 1). In terms of color, as shown in Fig. 2c, L1 is white, L2 is red, L3-L7 are varying shades of black, and L8 (i.e., the surface layer) is deep red-brown. In terms of thickness (Table 1), the lower 3 layers (L1, L2, and L3) and the upper 2 layers (L7 and L8) are thin and uniform, with a thickness of approximately $10-50 \mu \mathrm{m}$, whereas the middle layers (L4, L5, and L6) are thick and uneven, with a thickness of approximately 80-165 $\mu \mathrm{m}$. In terms of particle size (Fig. $2 \mathrm{~b}$ ), L4 and L5 are rough, and the particles contained within are large (maximum: $100 \mu \mathrm{m}$ ); L6 contains particles of a smaller size, with the maximum being approximately $60 \mu \mathrm{m}$; and the particles in the remaining layers are finer. Therefore, 


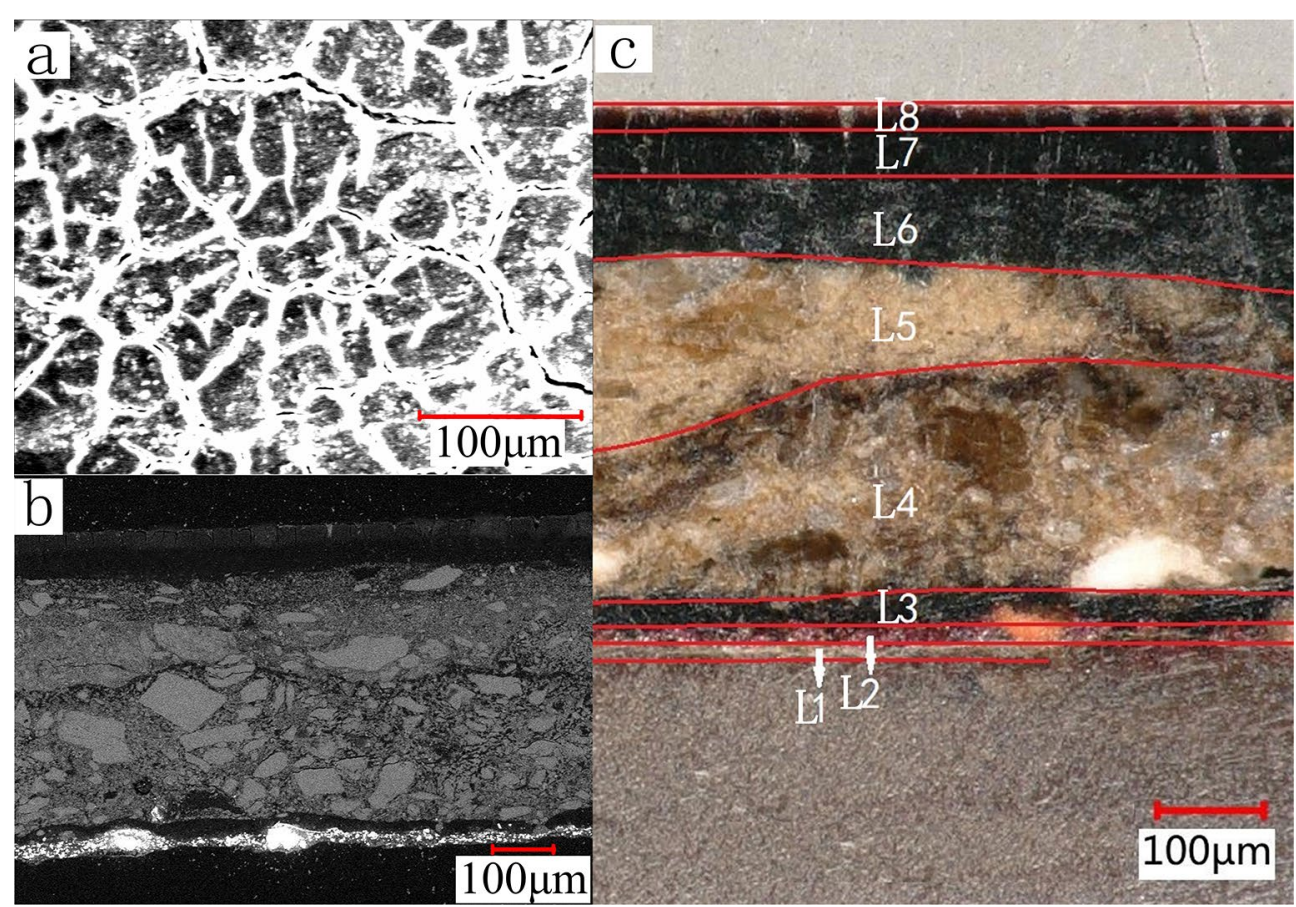

Fig. 2 SEM and OM images of the surface layer and cross-sections of the inscribed plaque: a $600 \times$ SEM secondary electron image of the surface layer. b $124 \times$ SEM backscatter image of the cross-sections. c $200 \times$ OM image of the cross-sections)

Table 1 Microstratigraphic hue, thickness, and SEM-EDS analysis results of the inscribed plaque

\begin{tabular}{|c|c|c|c|c|c|c|c|c|c|c|c|c|c|}
\hline \multirow{2}{*}{$\begin{array}{l}\text { Microstratigraphic sequence, hue, } \\
\text { thickness ( } \mu \mathrm{m})\end{array}$} & \multicolumn{13}{|c|}{ Element mass percent (\%) } \\
\hline & $\mathrm{C}$ & $\mathbf{O}$ & Mg & Al & Si & $\mathrm{S}$ & $\mathrm{Cl}$ & $\mathbf{K}$ & $\mathrm{Ca}$ & $\mathrm{Fe}$ & $\mathrm{Ba}$ & $\mathrm{Hg}$ & $\mathrm{Pb}$ \\
\hline L8, deep red-brown, approximately 35 & 36.11 & 41.47 & 0.69 & 2.62 & 8.54 & 1.65 & - & 1.22 & 3.71 & 1.27 & 2.72 & - & - \\
\hline L7, black, approximately 50 & 71.25 & 28.75 & - & - & - & - & - & - & - & - & - & - & - \\
\hline L6, black, 80-125 & 49.05 & 33.26 & - & - & 0.34 & 7.73 & - & - & 9.62 & - & - & - & - \\
\hline L5, dusty gray, 135-160 & 22.20 & 47.97 & - & - & - & 13.57 & - & - & 16.26 & - & - & - & - \\
\hline L4, gray, 133-165 & 41.68 & 28.86 & - & - & 1.13 & 12.28 & - & - & 16.05 & - & - & - & - \\
\hline L3, black, approximately 35 & 72.51 & 24.59 & - & - & 0.51 & 0.87 & - & - & 1.52 & - & - & - & - \\
\hline L2, red, approximately 30 & 57.49 & 20.72 & - & - & 0.34 & 2.77 & 0.40 & - & 0.87 & - & - & 14.35 & 3.06 \\
\hline L1, white, 10-20 & 38.77 & 38.39 & - & - & 1.69 & 1.03 & - & - & 20.11 & - & - & - & - \\
\hline
\end{tabular}

the cross-section was classified into 3 sections, i.e., the surface layer, plaster lacquer layer and primer lacquer layer. The surface layer was varnished twice (L7 and L8). The plaster lacquer layer was applied 3 times (L4, L5, and L6). The primer lacquer layer was applied 3 times (L1, L2 and L3). The ground layer (L1-L6) includes plaster lacquer layer and primer lacquer layer. In addition, interestingly, the surface layer (L8) appears glossy black to the naked eye; however, when observed under the $200 \times$ ultra-depth-of-field microscope, the surface layer (L8) appears deep red-brown and has a delicate micromorphology (Fig. 2c). In L2, the red pigment is mainly dark red and comprises fine particles, with a small amount of orange-red pigment, comprising larger and more nonuniform particles than those composing the dark red pigment.

\section{Decorative materials}

\section{SEM-EDS analysis}

The results of the SEM-EDS analysis are shown in Table 1. There is a large amount of $\mathrm{C}$ and $\mathrm{O}$ in each layer. Thus, it is speculated that every layer probably contains organic substances. There is a large amount of $\mathrm{C}, \mathrm{O}$, and $\mathrm{Ca}$ in the white substances in L1, the total content 


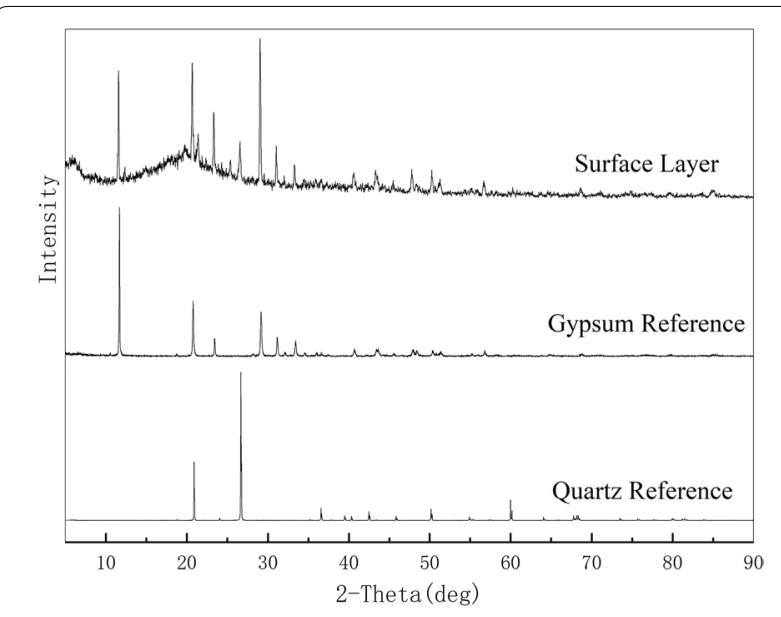

Fig. 3 XRD diagrams of the surface layer, gypsum reference, and quartz reference

of which exceeded 97\%. L2 contains $\mathrm{Hg}$ and $\mathrm{Pb}$, which might be the chromogenic elements of the red pigment. In L3 and L7, there is a large amount of C and O (97\%), while the content of other elements does not exceed 2.9\%. Moreover, L7 may only contain $\mathrm{C}$ and $\mathrm{O}$, with no other inorganic substances. In L4, L5, and L6, where the particle size is large, $\mathrm{Ca}$ and $\mathrm{S}$ contents are relatively high. In $\mathrm{L} 8$, in addition to a large amount of $\mathrm{C}$ and $\mathrm{O}$, elements such as $\mathrm{Si}, \mathrm{Al}, \mathrm{K}, \mathrm{Ca}, \mathrm{Fe}$ and $\mathrm{Ba}$ are also found, indicating that the surface is exposed to dust in the air.

\section{XRD analysis}

XRD analysis was carried out to reveal the inorganic components of the inscribed plaque. Figure 3 shows the XRD diagrams of the surface layer, gypsum, and quartz. The strong diffraction peaks of sample at $2 \theta$ of 11.6, 20.7 and 29.1 are consistent with the diffraction peaks of gypsum $\left(\mathrm{CaSO}_{4} \cdot 2 \mathrm{H}_{2} \mathrm{O}\right.$,JCPD:33-0311), and the diffraction peaks of sample at $2 \theta$ of 20.8 and 26.7 are consistent with those of quartz ( $\left.\mathrm{SiO}_{2}, \mathrm{JCPD}: 33-1161\right)$, indicating that there are gypsum and quartz in the surface layer. Moreover, quartz features weaker diffraction peaks, suggesting that the amount of quartz is lower than that of gypsum. As shown in Fig. 2a, there is a large number of cracks on the surface layer. Based on the EDS analysis (Table 1), layers L4-L6 contain a large amount of $\mathrm{Ca}$ and $\mathrm{S}$, possibly indicating the origin of gypsum. As shown in Table 1, the surface layer (L8) contained $\mathrm{Si}, \mathrm{Al}, \mathrm{Fe}$ and $\mathrm{K}$, which are common elements found in the soil. It is inferred that there was some dust on the surface of the inscribed plaque and that the quartz originated from the dust [10]. The sample has a mountain-shaped diffraction peak at $2 \theta$ of approximately 20, which means that the sample contains organic substances.
The XRD diagram of the red pigment of the back side of the sample in L2 is consistent with that of cinnabar (Fig. 4). Thus, the red pigment is probably cinnabar ( $\mathrm{HgS}$, $2 \theta$ at 26.5 and 31.2, JCPD:99-0031). The strong diffraction peaks indicates that the cinnabar features a good crystal form, high content, and few impurities in the red pigment. Based on the EDS analysis, the cinnabar comprises $3.06 \%$ of $\mathrm{Pb}$; however, the chromogenic phase of $\mathrm{Pb}$ was not detected in the XRD analysis. The possible reason is a very low $\mathrm{Pb}$ content; therefore, the peak is masked by the strong diffraction peaks of cinnabar, which contains $14.35 \%$ of $\mathrm{Hg}$.

Because there was a tiny amount of white substance of the back side of the sample in L1, $\mu$-XRD analysis was performed. The results show that the white substances are mainly calcite $\left(\mathrm{CaCO}_{3}, 2 \theta\right.$ at 29.4 and 47.6, JCPD:050586) and quartz (2 $\theta$ at 20.8 and 26.7, JCPD:33-1161), as shown in Fig. 5. The calcite has strong diffraction peaks,

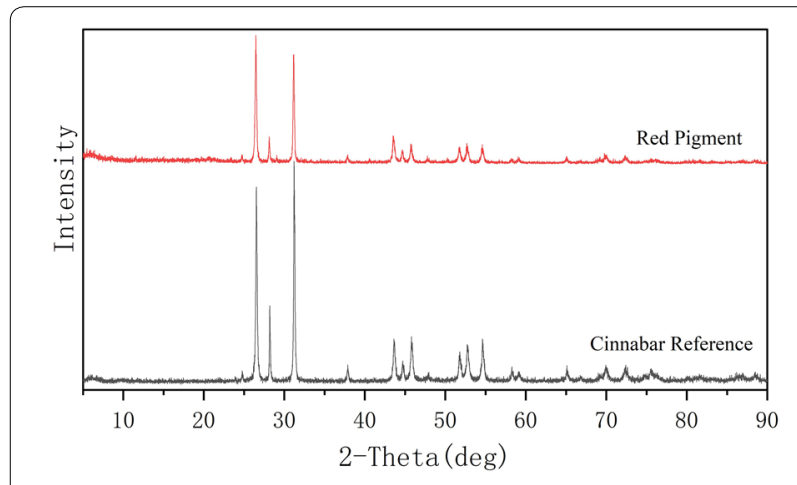

Fig. 4 XRD diagrams of the red pigment in the ground layer and the cinnabar reference

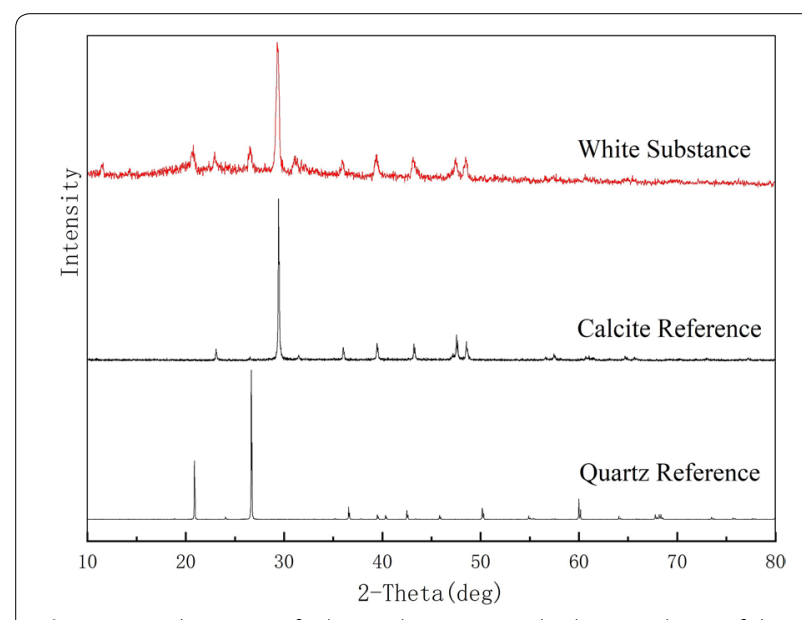

Fig. 5 XRD diagrams of white substances in the bottom layer of the ground layer of the inscribed plaque, calcite reference and quartz reference 

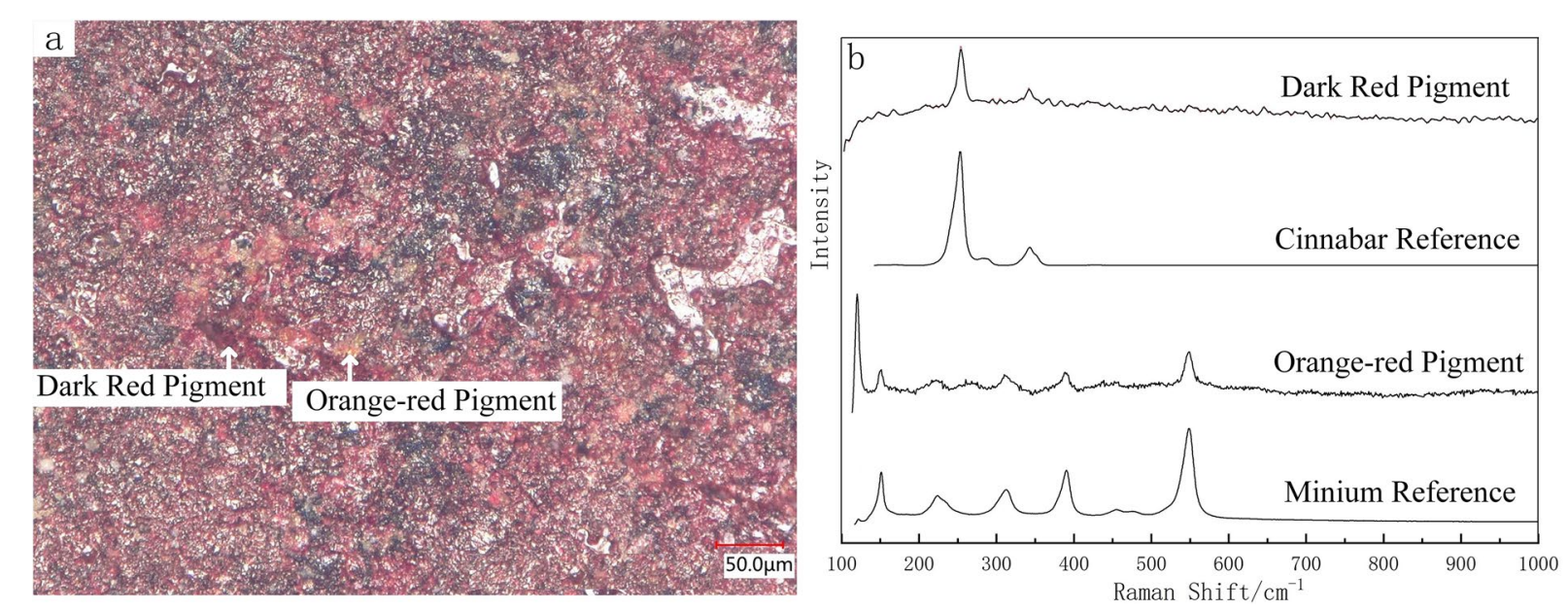

Fig. 6 a Microscopic image of the red pigment in L2 of the ground layer of the inscribed plaque. b Ramen spectra of the dark red pigment, orange-red pigment, cinnabar reference, and minium reference

and the quartz has weak diffraction peaks, suggesting a low quartz content.

\section{$\mu$-Raman analysis}

To reveal the $\mathrm{Pb}$ composition in the red pigment in $\mathrm{L} 2$ that was not detected by XRD analysis, $\mu$-Raman analysis was performed on the back side of the sample. Figure $6 \mathrm{a}$ shows the microscopic image of the red pigment by the configured microscope of a Raman spectrometer and Fig. 6b shows the Raman spectra of the dark red and orange-red pigments in L2 of the ground layer of the inscribed plaque. As seen, the Raman peaks of the dark red pigment at $253(\mathrm{vs})$ and $343(\mathrm{~m}) \mathrm{cm}^{-1}$ are basically consistent with the Raman peaks of cinnabar reference, while the Raman peaks of the orange-red pigment at 151(s), 224(m), 313(m), 390(s) and 549(vs) $\mathrm{cm}^{-1}$ are consistent with those of the minium reference. Based on the SEM-EDS analysis (Table 1), it is known that the red pigment in L2 is a mixture of cinnabar and minium, with a high cinnabar content and a low minium content.

\section{$\mu$-FTIR analysis}

To reveal the organic and inorganic substances in the decorative materials, $\mu$-FTIR analysis was performed on the samples. Figure 7 shows the $\mu$-FTIR spectra of the ground and the surface layer of the inscribed plaque as well as the reference FTIR spectra of current Chinese lacquer, the aged Chinese lacquer and gypsum. In the FTIR spectra of current Chinese lacquer, the aged Chinese lacquer and gypsum, the broad absorption band near $3428 \mathrm{~cm}^{-1}$ is the stretching vibration peak of $\mathrm{OH}$ [11]; at 2926 and $2854 \mathrm{~cm}^{-1}$, the absorption bands are the antisymmetric and symmetric stretching vibration peaks

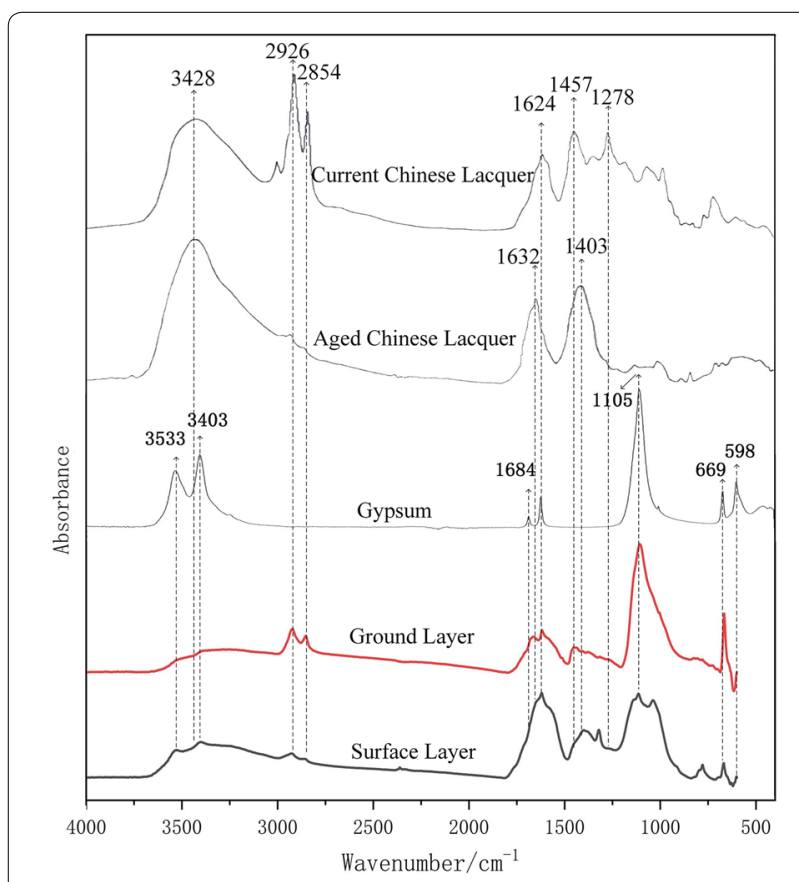

Fig. $7 \mu$-FTIR spectra of current Chinese lacquer, the aged Chinese lacquer, gypsum, the ground layer and surface layer of the plaque

of $\mathrm{CH}_{2}$ [12]; the weak absorption band at $1684 \mathrm{~cm}^{-1}$ is the characteristic absorption peak of $\mathrm{SO}_{4}{ }^{2-}$ [13]; the absorption band at 1632 and $1624 \mathrm{~cm}^{-1}$ is the stretching vibration peak of $\mathrm{C}=\mathrm{O}$ [14] and the characteristic absorption peak of $\mathrm{SO}_{4}{ }^{2-}$; the absorption band at 1457 and $1403 \mathrm{~cm}^{-1}$ is the stretching vibration band of $\mathrm{C}-\mathrm{O}$ [15]; the strong absorption band at $1105 \mathrm{~cm}^{-1}$ is the characteristic absorption peak of $\mathrm{SO}_{4}{ }^{2-}$; and the absorption 
bands at $669 \mathrm{~cm}^{-1}$ and $598 \mathrm{~cm}^{-1}$ are the characteristic absorption peaks of $\mathrm{SO}_{4}{ }^{2-}$.

Based on the characteristic infrared absorption peaks and the infrared spectrum of the surface layer, there are absorption peaks at 3428, 2926, 2854, 1624, and $1403 \mathrm{~cm}^{-1}$, indicating that the raw material is Chinese lacquer. The absorption peaks at 3533, 3403, 1105 and $669 \mathrm{~cm}^{-1}$ are characteristic absorption peaks of gypsum. The low intensity of these absorption peaks implies a low gypsum content in the sample. Because there were a large number of cracks in the surface layer of the sample, as shown in Fig. 2a, the components of the ground layer were detected. Based on the SEM-EDS results (Table 1), it can be concluded that gypsum was from the ground layer.

The infrared spectra of L1-L6 of the ground layer show that there are characteristic absorption peaks of Chinese lacquer at $3428,2926,2854$, and $1624 \mathrm{~cm}^{-1}$, indicating that the organic cement is Chinese lacquer. The absorption peaks at 3533, 3403, 1684, 1105, and $669 \mathrm{~cm}^{-1}$ are basically consistent with the characteristic absorption peaks of gypsum, confirming that gypsum is the inorganic substance in the ground layer. Based on the strong absorption peak at $1105 \mathrm{~cm}^{-1}$, the ground layer has a lower Chinese lacquer content and a higher gypsum content than the surface layer.

According to the infrared spectra of current Chinese lacquer and the aged Chinese lacquer, the absorption peak of current Chinese lacquer at $1278 \mathrm{~cm}^{-1}$ disappears after the aging. Also, the absorption peak near $1278 \mathrm{~cm}^{-1}$ is not found in the infrared spectra of the ground layer and surface layer of the sample, and it may be caused by the changes of in-plane bending vibration of $\mathrm{OH}$ and the stretching vibration of $\mathrm{C}-\mathrm{O}$ in Chinese lacquer [16].

Generally, the absorbance in infrared spectra measured by the $\mathrm{KBr}$ pellet method is significantly higher than that measured by ATR-FTIR [17], and ATR-FTIR absorption peaks decline remarkably within the range of $3600-3000 \mathrm{~cm}^{-1}$ [18]. The infrared spectra of current Chinese lacquer and the aged Chinese lacquer were obtained by the $\mathrm{KBr}$ pellet method [19], while that of the inscribed plaque was obtained by the $\mu$-ATR-FTIR method; therefore, the absorption peak of the sample close to $3428 \mathrm{~cm}^{-1}$ is low.

\section{Wood species of the base}

Figure 8 shows the microstructures of the wooden base of the inscribed plaque. The cross section is shown in Fig. 8a, with obvious growth rings and slow variation in the early and late wood features. The wood cells are tracheids with axial parenchyma cells; the tracheids of early wood have square and polygonal in the cross sections, and the tracheids of late wood show rectangular and polygonal in the cross sections. Figure $8 \mathrm{~b}$ shows the radial section of the wooden base; there are tracheid wall pits and cross field pits, and 2-4 small cypress cross field pits between ray parenchyma cells and early wood tracheids. Moreover, there is 1 row of round wall pits and scattered axial parenchyma cells; end wall nodular thickening of parenchyma cells containing dark resin is not obvious. Figure $8 \mathrm{c}$ shows the tangential section; there was a single row of rays with a height of 1-14 cells. All the ray cells are parenchyma cells without ray tracheid, and the ray parenchyma cells have few or insignificant

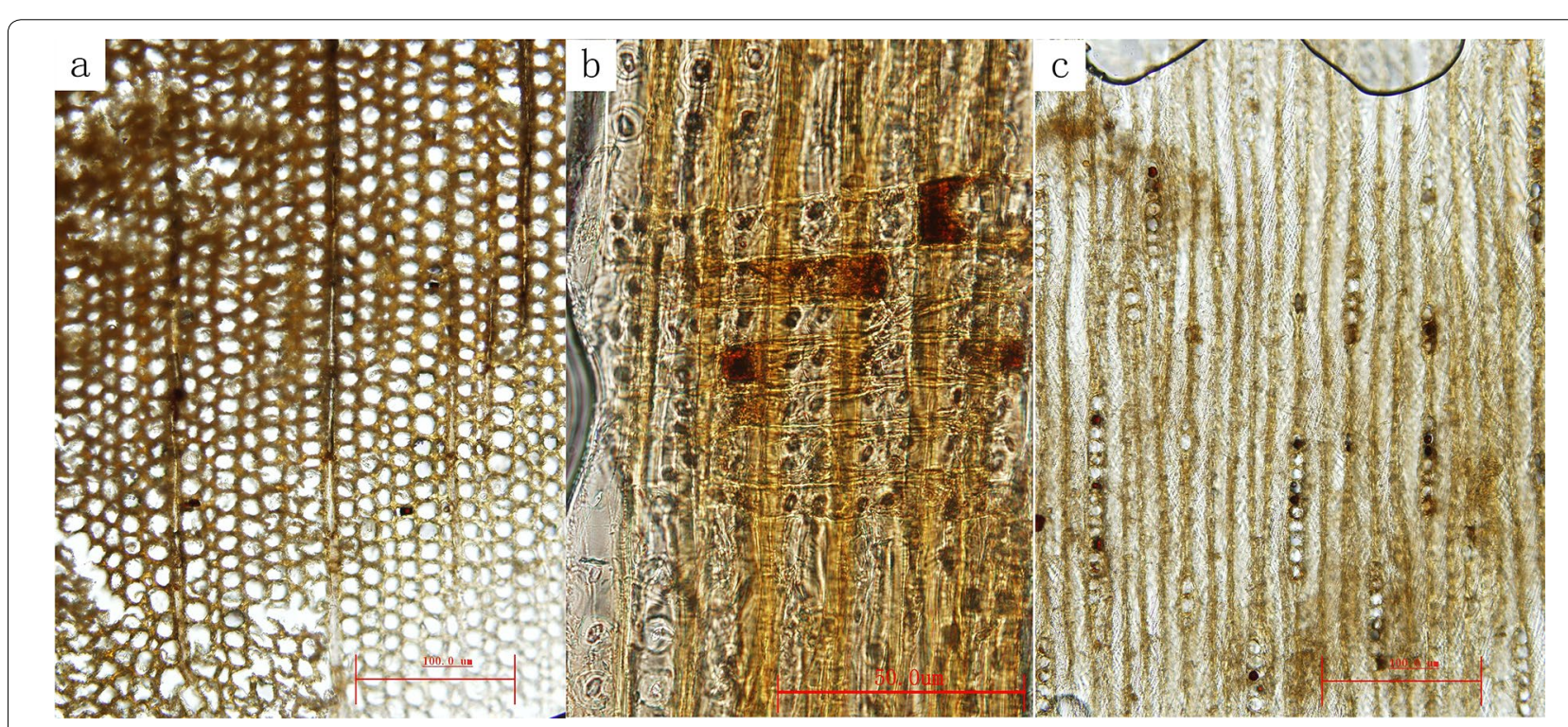

Fig. 8 Microstructures of the wooden base of the inscribed plaque: a Cross section. b Radial section. c Tangential section 
horizontal wall pits, with unobvious end wall nodular thickening and obvious dents.

According to the above microstructure characteristics of wood as well as existing data and images [20], it is determined that the wood species of the samples is a Cupressus species in the Cupressaceae family. Based on the distribution of Cupressus species in the Yangtze River basin in Sichuan Province, the wood should be Cupressus funebris.

\section{Lacquering technique}

Based on the results of the OM, SEM-EDS, XRD, $\mu$-FTIR and $\mu$-Raman analyses, the microstratigraphic sequences of decorative parts of the inscribed plaque consists of 8 microlayers. According to the hue, thickness, particle size, and material composition of each layer, the decorative parts were classified into 3 sections, i.e., the surface lacquer layer, plaster lacquer layer and primer lacquer layer. The surface lacquer layer, with Chinese lacquer as the main material, was varnished twice (L7 and L8). The layers are thin and even. The plaster lacquer layer was applied 3 times (L4, L5, and L6), with gypsum and Chinese lacquer as the raw material; the particles are coarse and uneven. The primer lacquer layer was applied 3 times (L1, L2 and L3). Calcite, the mixed pigments of cinnabar and minium and Chinese lacquer served as the main material to smooth the original surface of the wood. The ground layer includes plaster lacquer layer and primer lacquer layer. The wooden-cored inscribed plaque is made of cypress.

The materials used the inscribed plaque are all common decorative materials with a long history of application in ancient China. Cinnabar and calcite particles are fine, while minium particles are large and not uniform. Cinnabar and Chinese lacquer were used on the red wooden bowl unearthed at the Hemudu site in China, dating to approximately 7000 years ago [21], and exhibited outstanding durability. Minium was used in the Han Dynasty. The mixture of cinnabar and minium was used as the red pigment in Dunhuang wall paintings, and studies have shown that the mixture of cinnabar and minium makes the pigment more stable [22]. Because cinnabar and minium contain the heavy metal elements of $\mathrm{Hg}$ and $\mathrm{Pb}$, the mixture has bactericidal and anticorrosive. Gypsum is not only a white pigment commonly used in ancient wall paintings and polychrome cultural relics [23, 24] but also an inorganic gelling material that was used for architectural decoration in ancient China $[25,26]$.

The surface of the inscribed plaque was lacquered black, which was the most traditional technique for making lacquerware in ancient China. The surface of the lacquer film appears glossy black to the naked eye but appears deep red-brown in OM images. An early record of the production of black lacquer is found in Nan Cun Chuo Geng Lu-Xiu Qi(南村辍耕录。髹器) written by Tao Zongyi in the Yuan Dynasty [27]: Chinese lacquer was boiled, and then the waste iron filings were soaked in rice vinegar to produce the black lacquer. The process may involve the following reactions:

$$
\begin{aligned}
& \mathrm{CH}_{3} \mathrm{COOH}+\mathrm{Fe}_{2} \mathrm{O}_{3} \rightarrow \mathrm{Fe}(\mathrm{OH})\left(\mathrm{CH}_{3} \mathrm{COO}\right)_{2}+\mathrm{H}_{2} \mathrm{O} \\
& \mathrm{Fe}(\mathrm{OH})\left(\mathrm{CH}_{3} \mathrm{COO}\right)_{2}+\mathrm{H}_{2} \mathrm{O} \rightarrow \mathrm{Fe}(\mathrm{OH})_{2} \downarrow \\
& \quad(\text { white })+\mathrm{CH}_{3} \mathrm{COOH} \\
& \mathrm{Fe}(\mathrm{OH})_{2}+\mathrm{O}_{2}+\mathrm{H}_{2} \mathrm{O} \rightarrow \mathrm{Fe}(\mathrm{OH})_{3} \downarrow \text { (bluish green) }
\end{aligned}
$$

Coated onto a glass sheet, the black lacquer dyed with iron filings turns deep red-brown under bright light [28], which is consistent with the surface color of the crosssection of the inscribed plaque observed under OM.

The primer of the inscribed plaque is likely gypsum lacquer plaster (lacquer mixed with gypsum), which has lasted for more than 150 years without serious falling off, indicating excellent performance of this technique. As recorded in Xiu Shi $L u$ (髤饰录) by Huang Cheng in the Ming Dynasty, the ground layer was usually made from materials such as horn ash, bone ash, clam ash, brick ash, pig blood, and tung oil plaster [2]; gypsum was not mentioned at all. Records regarding gypsum lacquer plaster can be found in Essentials about Lacquerware Techniques(漆器工艺技法倾要) by Shen and Li [29]. Adding Chinese lacquer into gypsum can accelerate the drying of lacquer plaster, and the mixed material is more solid than gypsum mixed with pig blood. With the ability to gelate, gypsum may biomineralize with substances in Chinese lacquer such as urushiol and laccase, but the scientific principles remain to be further explored. Gypsum lacquer plaster is a commonly used material for making the ground layer of lacquerware in modern times [30]. This study confirmed that the technique of making lacquerware with gypsum lacquer plaster existed in the Bashu area during the late Qing Dynasty.

\section{Conclusions}

In this study, we used a number of technologies, including OM, SEM-EDS, XRD, $\mu$-Raman and $\mu$-FTIR, to analyze the materials and techniques for the production of the "Chun Rong Xuan Mao" birthday inscribed plaque in the Bashu area of China in the 5th year during the reign of Tongzhi Emperor of the Qing Dynasty (A.D. 1866). We found that (1) cypress wood was the base material for the inscribed plaque, which symbolizes the gift of presenter's best wishes for the elderly, i.e., nobility and longevity; (2) the decorative parts on 
the inscribed plaque have 3 sections, i.e., the surface lacquer layers, plaster lacquer layers and primer lacquer layers. Black lacquering techniques were used in the surface lacquer layers, and a gypsum lacquer plaster technique was used in the ground layer. The surface lacquer was varnished twice, with Chinese lacquer as the main raw material; the 2 layers were delicate, thin and even. The plaster lacquer was applied 3 times, with gypsum and Chinese lacquer as the raw material; the particles were coarse and uneven. The primer lacquer was applied 3 times, and calcite, the mixed pigments of cinnabar and minium and Chinese lacquer were the main materials used to smooth the original surface of the wooden base. Gypsum lacquer plaster is a commonly used material to make the ground layer of lacquerware in modern times. This study confirmed the existence of technology to make lacquerware using gypsum lacquer plaster in the Bashu area during the late Qing Dynasty. By providing new evidence for traditional techniques of producing inscribed plaques and offering technical support for the protection and restoration of inscribed plaques, the current study is of great significance to exploring the history of ancient techniques for lacquering and decorating lacquerware.

\section{Abbreviations \\ OM: Optical microscopy; SEM-EDX: Scanning electron microscopy with energy dispersive $X$-ray spectroscopy; XRD: $X$-ray diffraction; $\mu$-Raman: Micro-Raman spectroscopy; $\mu$-ATR-FTIR: Micro-Attenuated total reflection Fourier transform Infrared spectroscopy.}

\section{Acknowledgements}

We are grateful to Sun Cunchong (China Three Gorges Museum, Chongqing, China) for providing the Raman data and Museum of Chongqing Normal University for providing the samples. $\mu$-ATR-FTIR and XRD experiments were performed on the Key Laboratory of Cultural Heritage Research and Conservation, Ministry of Education (Northwest University), Xi'an, Shaanxi Province, China and OM experiments were performed on Key Laboratory of Archaeometry and Cultural Relics Preservation (Chongqing Normal University), Chongqing, Chongqing Municipality, China for which the authors give thanks.

\section{Authors' contributions \\ LZ and LW performed the data analysis and were major contributors in writing the manuscript. XZ provided the data processing method of infrared spectrum. JY and MZ made the cross-section sample. YW provided process- ing method of microscopic image. All authors read and approved the final manuscript.}

\section{Funding}

This research was supported by the National Social Science Foundation of China (17XKG002) and the Key Research and Development Program of Shaanxi Province, China (2019ZDLSF07-05).

\section{Availability of data and materials}

The datasets used and/or analyzed during the current study are available from the corresponding author on reasonable request.

\section{Competing interests}

The authors declare that they have no competing interests.

\section{Author details}

${ }^{1}$ School of Cultural Heritage, Northwest University, Xi'an 710127, China. ${ }^{2}$ College of History and Society, Chongqing Normal University, Chongqing 401331 , China. ${ }^{3}$ Chongqing Institute of Engineering, Chongqing 401320, China.

${ }^{4}$ Yichang Three Gorges Secondary Vocational School, Yichang 443100, China.

Received: 13 August 2020 Accepted: 1 November 2020

Published online: 16 November 2020

References

1. Li X. Ying Zao Fa Shi(营造法式), volume 21: The size of the material of Joinery work 2-inscribed plaques. Northern Song Dynasty (in Chinese).

2. Wang SX. Explanation of Xiu Shi Lu(鬆饰录): A study on the traditional Chinese lacquer craft. Beijing: Cultural Relics Publishing House; 1998. p.5$45,67,70$ (in Chinese).

3. Zhou ZB, Shen L, Li CL, Wang N, Chen XL, Yang J, Zhang H. Investigation of gilding materials and techniques in wall paintings of Kizil Grottoes. Microchem J. 2020;154:104548.

4. Ma ZZ, Yan J, Zhao X, Wang LQ, Yang Lu. Multi-analytical study of the suspected binding medium residues of wall paintings excavated in Tang tomb, China. J Cult Herit. 2017; 24:171-174.

5. Qin PF, Yi DQ, Meng Q, Sun AJ, Sun JQ. Study and restoration of the Yi Ma Wu Hui layer of the ancient coating on the Putuo Zongcheng Temple. Int J Archit Herit. 2020;1(5):1-15.

6. Wang LQ, Yang L, Zhou WH, Yan J, Guo R. Analysis of the techniques and materials of the colored paintings in the Renshou Hall in the Summer Palace. Anal Methods. 2015;7(12):5334-7.

7. Fu YC, Chen ZF, Zhou SL, Wei SY. Comparative study of the materials and lacquering techniques of the lacquer objects from Warring States Period China. J Archaeol Sci. 2020;114:105060.

8. Hao XY, Schilling MR, Wang X, Khanjian H, Heginbotham A, Han J, Auffretb S, Wu XJ, Fang BS, Tong H. Use of THM-PY-GC/MS technique to characterize complex, multilayered Chinese lacquer. J Anal Appl Pyrol. 2019;140:339-48.

9. Karpova E, Nefedov A, Mamatyuk Victor, Polosmak N, Kundo L. Multi-analytical approach (SEM-EDS, FTIR, Py-GC/MS) to characterize the lacquer objects from Xiongnu burial complex (Noin-Ula, Mongolia). Microchem J. 2017; 130:336-344.

10. Shen ZX, Zhang XY, Cao JJ, Mei FM, Lu HY. Mineralogical analysis for the atmospheric dust samples. Rock Miner Anal. 2003;22(3):165-8 (in Chinese with English abstract).

11. Li D, Xu FG. The study of the possibility of silicon dioxide coatings modified by (3-aminoprropyl) triethoxysilane as protective materials for stone. J Coat Technol Res. 2020;17(2):563-72.

12. Jin PJ, Hu YL, Ke ZB. Characterization of lacquer films from the middle and late Chinese warring states period 476-221BC. Microsc Res Techniq. 2017;80(12):1344-50.

13. Yan W, Zeng BL, Meng J, Wang SM, Liang SW. Study on the identification of gypsum fibrosum with FTIR. Spectrosc Spect Anal. 2016;36(7):2098103 (in Chinese with English abstract).

14. Wang R, Nie F, Chen JM, Zhu Y. Studies On Lacquerwares from Between the Mid-Warring States Period and the Mid-Western Han Dynasty Excavated in the Changsha Region. Archaeometry. 201; 59(3): 547-565.

15. Liu HJ, Sun SQ, Li A, Ha YM. Quality Analysis of Spirulina Products Using Three-Step Infrared Spectroscopy. Scientia Agricultura Sinica. 2012;45(22):4738-48 (in Chinese with English abstract).

16. Zheng JB, Shan WF, Zhang W, Guo SQ. Infrared spectra of ancient lacquer objects. J Fudan Univ (Nat Sci). 1992;31 (3):345-9 (in Chinese with English abstract).

17. Pei YF, Zuo ZT, Zhao YL, Zhang QZ, Wang YZ. Identification of Paris polyphylla Smith var. yunnanensis from Different Origins Using FTIR, ATR-FTIR and UV Multispectral Data. J Anal Sci. 2019; 38(1): 14-21 (in Chinese with English abstract).

18. Tao LZ, Pan ZJ, Jiang YX, Qin DK. Application of ATR-FTIR on textile fiber qualitative identification. Shanghai Textile Sci. Tech. 2009;37(9):16-9 (in Chinese with English abstract).

19. He L, Wang N, Liang JY, Li HX. The effect of hematite and malachite to the aging of tung oil and Chinese lacquer. Herit Museum. 2009;6:269-75 (in Chinese with English abstract). 
20. Chen JQ, Yang JJ, Liu P. Atlas of woods of china. Beijing: China Forestry Publishing House;1992. p. Plate 2, 6, 9-10 (in Chinese).

21. Xia Y. Chinese historical pigments in polarized light microscope. Beijing: Science Press; 2017. p. 22, 27 (in Chinese).

22. Su BM, Hu ZD, Li ZX. A study of the mixed pigments used in the wall painting of Dunhuang. Dunhuang Res. 1996;3:149-62 (in Chinese with English abstract).

23. Denisse LA, Gloria T, Genoveva HP, Verónica O, Pedro AL, Víctor MC. Cinnabar, hematite and gypsum presence in mural paintings in Teotihuacan Mexico. J Archaeol Sci. 2020;32:102375.

24. Antunes V, Candeias A, Oliveira M. Characterization of gypsum and anhydrite ground layers in 15th and 16th centuries Portuguese paintings by Raman Spectroscopy and other techniques. J Raman Spectrosc. 2014;45:1026-33.

25. La SV, Grau G, Carles J. Uses of gypsum in Spanish architectural heritage: typologies and some unique. Int J Archit Herit. 2020;14(2):176-95.
26. Garrote MA, Robador MD, Perez-Rodriguez JL. Analytical investigation of Mudéjar polychrome on the carpentry in the Casa de Pilatos palace in Seville using non-destructive XRF and complementary techniques. Spectrochim Acta A. 2017;173:279-91.

27. Tao ZY. Nan Cun Chuo Gen Lu-Xi Qi (南村辍耕录·髹器), volume 31: lacquerware, Yuan Dynasty (in Chinese).

28. Cao SL. Study on the color of Chinese lacquer. J Chinese Lacquer. 1985;2:21-7 (in Chinese).

29. Shen FW, Li DS. Essentials about lacquerware techniques. Beijing: Light Industry Press; 1984. p. 39-40 (in Chinese).

30. Bian JY. Chinese ancient architecture painting. Beijing: China Building Materials Industry Press; 2013, p. 45 (in Chinese).

\section{Publisher's Note}

Springer Nature remains neutral with regard to jurisdictional claims in published maps and institutional affiliations.

\section{Submit your manuscript to a SpringerOpen ${ }^{\circ}$ journal and benefit from:}

- Convenient online submission

- Rigorous peer review

- Open access: articles freely available online

- High visibility within the field

- Retaining the copyright to your article

Submit your next manuscript at $\boldsymbol{\text { springeropen.com }}$ 